\title{
Consumo, digestibilidade dos nutrientes e comportamento ingestivo de vacas leiteiras alimentadas com castanha de caju
}

\author{
[Intake, digestibility of nutrients and ingestive behavior of dairy cows fed with cashew nut] \\ P.G. Pimentel ${ }^{1}$, R.B. Reis ${ }^{2 *}$, L.A. Leite ${ }^{2}$, W.E. Campo $^{3}$, J.N.M. Neiva ${ }^{4}$, \\ H.M. Saturnino ${ }^{2}$, S.G. Coelho ${ }^{2}$ \\ ${ }^{1}$ Universidade Federal do Ceará - Fortaleza, Ce \\ ${ }^{2}$ Escola de Veterinária - UFMG - Belo Horizonte, MG \\ ${ }^{3}$ Fiscal Federal Agropecuário do MAPA - Brasília, DF \\ ${ }^{4}$ Escola de Medicina Veterinária e Zootecnia - UFT - Araguaína, TO
}

\begin{abstract}
RESUMO
Avaliou-se o efeito da inclusão de castanha de caju (CC) - 0, 8, 16 e 24\% - na porção concentrada da ração sobre o consumo, a digestibilidade aparente dos nutrientes e o comportamento ingestivo em oito vacas Holandesas pluríparas, com produção média de $28 \pm 4 \mathrm{~kg}$ de leite/dia, dispostas em delineamento quadrado latino $4 \times 4$, duplo. A silagem de milho foi utilizada como alimento volumoso único. A CC contribuiu com, aproximadamente, 46,0; 61,8 e 67,7\% do total de extrato etéreo presente no concentrado quando a inclusão foi de 8,16 e $24 \%$, respectivamente. O consumo de matéria seca não foi alterado em função da inclusão de CC na ração, apresentando valor médio de $21,29 \mathrm{~kg} / \mathrm{dia}$. A digestibilidade da matéria seca e dos nutrientes apresentaram variações que não foram relacionadas ao aumento no teor de lipídeos das dietas. Embora tenha sido observada redução no tempo de ingestão de matéria seca, o tempo despendido com a ruminação possibilitou que a atividade mastigatória não fosse afetada pela suplementação lipídica. A maior proporção de CC adicionada ao concentrado, 24\%, não influenciou o consumo, a digestibilidade aparente dos nutrientes e o comportamento ingestivo, dessa forma pode ser recomendada como alternativa potencial na alimentação de vacas leiteiras em lactação.
\end{abstract}

Palavras-chave: gado leiteiro, atividade mastigatória, coprodutos, lipídeos, ruminação

\begin{abstract}
The effect of the inclusion of cashew nut $(C N)$ at the amounts of $0,8,16$ e $24 \%$ in the concentrate portion of the ration on the intake, apparent digestibility of nutrients and ingestive behavior was evaluated, using eight Holstein dairy cows, producing $28 \pm 4 \mathrm{~kg}$ milk/day, allocated in a $4 x 4$ double Latin Square Design. Corn silage was used as main forage. The CN contributed with approximately 46.0; 61.8 and $67.7 \%$ of total ether extract present in the concentrate when the inclusion levels were 8, 16 and 24\%, respectively. The dry matter intake was not altered by the inclusion of $C N$ in the rations, showing mean value of $21.29 \mathrm{~kg} /$ day. The digestibility of dry matter and nutrients showed variations that were not related to the increased lipid content of the rations. Although reductions have been observed in the time spent with dry matter intake, the time spent ruminating enabled the chewing activity to not be affected by fat supplementation. The highest proportion of CN added to the concentrate (24\%) did not influence the intake, apparent digestibility and ingestive behavior, so it can be recommended as a potential alternative for feeding dairy cows.
\end{abstract}

Keywords: dairy cow, chewing activity, coproducts, lipids, rumination

Recebido em 2 de março de 2011

Aceito em 12 de fevereiro de 2012

*Autor para correspondência (corresponding author)

E-mail: rbreis@vet.ufmg.br

Apoio financeiro: Banco do Nordeste do Brasil 


\section{INTRODUÇÃO}

A alimentação destaca-se entre os itens que mais oneram a produção de leite, representando a maior parcela do custo total da atividade, sendo necessária, portanto, utilização criteriosa dos alimentos disponíveis na propriedade para que se possa atingir maior eficiência econômica (Villela et al., 2006). A elevação e a oscilação nos preços dos componentes concentrados, tanto energéticos quanto proteicos, apontam para a necessidade de se avaliar a possível substituição destes por alimentos alternativos de menor custo e que, apresentando adequada qualidade, sejam capazes de manter a produção dos rebanhos.

Uma alternativa cujo potencial é ainda pouco explorado é a inclusão de coprodutos na formulação de dietas para animais em produção, substituindo os alimentos convencionais. Os resíduos da agroindústria podem consistir em fontes valiosas de proteína, energia e fibra. No entanto, como a variabilidade no conteúdo de nutrientes é maior para os coprodutos que para os alimentos convencionais, análises frequentes de sua composição química devem ser realizadas para obtenção de melhores resultados (Lima, 2005).

Com o desenvolvimento da fruticultura, a região Nordeste vem apresentando significativo aumento no número de agroindústrias instaladas, resultando em elevada produção de resíduos agroindustriais com alto potencial de utilização na ração animal, tornando-se importante recurso a ser usado na redução dos custos de produção (Lousada Junior et al., 2006). Dentre as plantas frutíferas tropicais, o cajueiro ocupa lugar de destaque no setor da agroindústria. O caju é composto pela castanha - verdadeiro fruto - e pelo pseudofruto - pedúnculo hipertrofiado. A castanha de caju contém em seu interior a amêndoa, que, tostada, representa elevado valor comercial (Lavezzo, 1995). A partir das perdas no beneficiamento industrial da amêndoa, obtémse o coproduto da castanha de caju, impróprio ao consumo humano, e que, por possuir satisfatória composição de nutrientes, pode ser uma alternativa viável no arraçoamento de vacas leiteiras, substituindo o milho e o farelo de soja, ingredientes que mais oneram o custo da ração.

A presente pesquisa teve como finalidade avaliar o consumo e a digestibilidade aparente da matéria seca e nutrientes, bem como o comportamento ingestivo de vacas leiteiras em lactação, alimentadas com dieta com proporções crescentes de castanha de caju.

\section{MATERIAL E MÉTODOS}

Foram utilizadas oito vacas Holandesas pluríparas, entre 50 e 74 dias pós-parto, com produção média de $28 \pm 4 \mathrm{~kg}$ de leite/dia, peso corporal médio de $555 \mathrm{~kg}$, dispostas em delineamento quadrado latino $4 \times 4$, duplo. A pesquisa teve duração de 84 dias, divididos em quatro períodos de 21 dias, sendo 14 dias de adaptação e sete dias para coleta de dados. Os animais permaneceram confinados e individualizados em instalações do tipo tie stall com livre acesso à água.

Os tratamentos avaliados consistiram na inclusão de $0,8,16$ e $24 \%$ de castanha de caju moída (CC) na porção concentrada da ração (Tab. 1).

As dietas foram equilibradas para atender às exigências nutricionais das vacas de acordo com o Nutrient... (2001). A ração foi fornecida na forma de mistura completa, duas vezes ao dia, após as ordenhas, às sete e às 17 horas, para permitir sobras de $10 \%$. Antes da primeira alimentação do dia, as sobras foram coletadas e pesadas para ajuste do consumo de cada animal. A silagem de milho foi utilizada como alimento volumoso único $\mathrm{e}$ as rações foram formuladas para serem isoproteicas. A relação volumoso:concentrado utilizada foi 50:50.

Os teores de extrato etéreo na ração com $0,8,16$ e $24 \%$ de CC na porção concentrada foram, respectivamente, 3,$16 ; 4,60 ; 6,89$ e 7,31\%, com base na matéria seca (Tab. 2). A castanha de caju contribuiu com, aproximadamente, 46,0; 61,8 e $67,7 \%$ do total de extrato etéreo presente nos concentrados quando a inclusão deste ingrediente foi de 8,16 e $24 \%$, respectivamente. 


\section{Pimentel et al.}

Tabela 1. Composição bromatológica da silagem de milho, da castanha de caju (CC) e dos concentrados experimentais

\begin{tabular}{lcccccc} 
Nutriente & \multirow{2}{*}{$\begin{array}{c}\text { Silagem de } \\
\text { milho }\end{array}$} & CC & \multicolumn{4}{c}{ Concentrado } \\
\cline { 5 - 7 } & 39,64 & 94,05 & 90,48 & 90,02 & 91,24 & 90,57 \\
MS & 8,64 & 24,45 & 26,75 & 25,52 & 25,70 & 25,29 \\
PB & 5,13 & 44,09 & 3,59 & 8,20 & 11,68 & 15,58 \\
EE & 82,83 & 25,34 & 61,24 & 57,86 & 55,16 & 50,91 \\
CHOT $^{1}$ & 32,27 & 8,46 & 34,64 & 35,17 & 31,56 & 28,94 \\
CNF $^{2}$ & 50,56 & 16,88 & 26,59 & 22,68 & 23,66 & 21,97 \\
FDN $^{\text {FDA }}$ & 29,15 & 9,38 & 13,73 & 14,07 & 15,36 & 15,02 \\
Cinzas & 3,40 & 6,12 & 8,43 & 8,43 & 7,40 & 8,22 \\
Ca & 0,37 & 0,42 & 1,52 & 1,47 & 1,44 & 1,46 \\
P & 0,18 & 0,81 & 0,73 & 0,57 & 0,65 & 0,72 \\
EB, Mcal/kg & 4,34 & 6,56 & 4,24 & 4,33 & 4,65 & 4,70 \\
\hline
\end{tabular}

C00: sem CC; C08: 8\% de CC; 1 16: $16 \%$ de CC; C24: 24\% de CC.

MS: matéria seca; PB: proteína bruta; EE: extrato etéreo; CHOT: Carboidratos totais; CNF: carboidratos não fibrosos; FDN: fibra em detergente neutro; FDA: fibra em detergente ácido; Ca: cálcio; P: fósforo; EB: energia bruta. ${ }^{1} \% \mathrm{CHOT}=100-(\% \mathrm{~PB}+\% \mathrm{EE}+\%$ Cinzas $)$, de acordo com Sniffen et al. (1992).

${ }^{2} \% \mathrm{CNF}=100-(\% \mathrm{~PB}+\% \mathrm{FDN}+\% \mathrm{EE}+\%$ Cinzas $)$, de acordo com Nutrient... (2001).

Tabela 2. Composição centesimal e química das dietas experimentais com diferentes proporções de castanha de caju

\begin{tabular}{|c|c|c|c|c|}
\hline \multirow{2}{*}{ Ingrediente (\%MS) } & \multicolumn{4}{|c|}{ Inclusão de castanha de caju (\%) } \\
\hline & 00 & 08 & 16 & 24 \\
\hline Silagem de milho & 50,00 & 50,00 & 50,00 & 50,00 \\
\hline Castanha de caju & 0,00 & 3,76 & 7,53 & 11,29 \\
\hline Milho, grão moído & 18,15 & 14,58 & 13,13 & 12,44 \\
\hline Farelo de soja & 18,09 & 16,55 & 14,68 & 12,85 \\
\hline Polpa de citros & 11,33 & 12,95 & 12,39 & 10,82 \\
\hline Ureia & 0,32 & 0,32 & 0,32 & 0,32 \\
\hline Premix min-vit ${ }^{1}$ & 0,64 & 0,64 & 0,65 & 0,65 \\
\hline Cloreto de sódio & 0,27 & 0,27 & 0,27 & 0,27 \\
\hline Calcário & 0,32 & 0,32 & 0,27 & 0,43 \\
\hline Bicarbonato de sódio & 0,27 & 0,27 & 0,27 & 0,27 \\
\hline \multicolumn{5}{|l|}{ Nutriente $(\% \mathrm{MS})$} \\
\hline MS & 50,18 & 51,25 & 50,02 & 49,40 \\
\hline PB & 15,77 & 16,22 & 15,36 & 14,59 \\
\hline $\mathrm{EE}$ & 3,16 & 4,60 & 6,89 & 7,31 \\
\hline CHOT & 75,15 & 73,92 & 71,93 & 71,85 \\
\hline $\mathrm{CNF}$ & 29,64 & 28,07 & 27,63 & 27,82 \\
\hline FDN & 45,51 & 45,85 & 44,30 & 44,03 \\
\hline FDA & 29,87 & 28,07 & 27,63 & 27,82 \\
\hline Cinzas & 5,92 & 5,26 & 5,82 & 6,25 \\
\hline $\mathrm{Ca}$ & 0,74 & 0,78 & 0,78 & 0,72 \\
\hline $\mathrm{P}$ & 0,30 & 0,34 & 0,34 & 0,31 \\
\hline
\end{tabular}

00: sem CC; 08: com 8\% de CC na porção concentrada; 16: com 16\% de CC na porção concentrada; 24: com 24\% de CC na porção concentrada.

${ }^{1}$ Composição por kg: Ca: 21,0\%; P: 16,0\%; S: 2,1\%; Fe: 2000ppm; Cu: 2000ppm; Zn: 5000ppm; Mn: 1600ppm; I: 160ppm; Se: 30ppm; Co: 185ppm; F(máx): 1600ppm. 
Os teores de FDN e FDA de todas as dietas experimentais situaram-se acima do mínimo de 28 e $21 \%$, respectivamente, segundo o recomendado pelo Nutrient... (2001).

À medida que a castanha de caju foi incluída na ração, observou-se uma substituição gradual dos ingredientes milho e soja, como mostra a Tab. 2 . $\mathrm{O}$ milho foi substituído pela $\mathrm{CC} \mathrm{em}$, aproximadamente, 19,$7 ; 27,7$ e $31,5 \%$, enquanto o farelo de soja apresentou proporção de substituição de, aproximadamente, 8,5; 18,9 e $29,0 \%$, nas dietas com 8,16 e $24 \%$ de CC na porção concentrada, respectivamente.

O consumo voluntário diário foi obtido pela subtração da quantidade de alimento fornecido nas duas alimentações pela sobra pesada na manhã seguinte antes da primeira alimentação do dia. Amostras do oferecido e das sobras foram coletadas diariamente, acondicionadas em sacos plásticos devidamente identificados e armazenados a $-20^{\circ} \mathrm{C}$ para posteriores análises laboratoriais.

As fezes foram coletadas pela manhã e à tarde, do $15^{\circ}$ ao $20^{\circ}$ dia do período experimental, diretamente da ampola retal, sendo realizadas ao final do dia amostras compostas para obtenção de uma só amostra por animal, as quais foram acondicionadas em sacos plásticos identificados e armazenados a $-20^{\circ} \mathrm{C}$. Para determinação da produção fecal, foi utilizada a concentração de lignina como marcador interno, nas amostras da ração fornecida e nas sobras e fezes (Van Soest, 1994).

Ao término do experimento, as amostras do fornecido das sobras e das fezes foram descongeladas à temperatura ambiente e compostas por animal por período. A présecagem destas amostras foi realizada em estufa de ventilação forçada, a $65^{\circ} \mathrm{C}$, durante 72 horas, e, posteriormente, estas foram moídas em moinho do tipo Thomas Willey (modelo 4, Arthur H. Thomas Co., Philadelphia PA), dotado de peneira com crivos de $1 \mathrm{~mm}$, acondicionadas em recipientes de plástico com tampa e armazenadas para posteriores análises laboratoriais.

Os teores de matéria seca (MS), cinzas, proteína bruta $(\mathrm{PB})$, extrato etéreo $(\mathrm{EE})$, cálcio $(\mathrm{Ca})$ e fósforo $(\mathrm{P})$ foram determinados segundo a
Official... (1995). As análises de fibra em detergente neutro (FDN) e fibra em detergente ácido (FDA) foram realizadas de acordo com o método de Van Soest et al. (1991). A diferença entre os teores de matéria seca e cinzas determinou a matéria orgânica (MO).

A porcentagem de carboidratos não fibrosos (CNF) foi calculada segundo a equação proposta pelo Nutrient... (2001): \%CNF $=100-(\%$ PB + $\%$ FDN $+\%$ EE $+\%$ Cinzas). Os teores de carboidratos totais (CHOT) foram obtidos a partir da fórmula (Sniffen et al., 1992): \%CHOT $=100-(\% \mathrm{~PB}+\% \mathrm{EE}+\%$ Cinzas $)$.

Os cálculos da produção fecal (PF) e do coeficiente de digestibilidade aparente (\%DA) foram obtidos a partir das seguintes expressões (Church, 1988): PF (gMS/dia) = lignina consumida (g/dia)/concentração de lignina nas fezes $(\mathrm{g} / \mathrm{gMS})$ e $\% \mathrm{DA}=$ [nutriente ingerido (kg/dia) - nutriente excretado nas fezes ( $\mathrm{kg} / \mathrm{dia})] /$ nutriente ingerido $(\mathrm{kg} / \mathrm{dia}) \times 100$.

O comportamento ingestivo foi determinado no $20^{\circ}$ e $21^{\circ}$ dia de cada período experimental, por meio da observação visual da atividade bucal de cada animal, de forma intermitente a cada cinco minutos, durante 24 horas seguidas. A avaliação do comportamento ingestivo consistiu no registro do tempo despendido com as atividades de ruminação, ócio e ingestão de água e alimentos. Os tempos de mastigação foram determinados pela soma dos tempos de ingestão de alimentos e ruminação (minutos/dia). Para os tempos de mastigação (minutos/dia) por unidade de matéria seca consumida, foram considerados os consumos médios de cada período (Johnson e Combs, 1991).

Os resultados foram interpretados estatisticamente por meio de análise de contrastes para determinar se as respostas obtidas comportavam-se com padrões linear ou quadrático. A análise de regressão foi realizada para a obtenção de estimativas das respostas avaliadas com a inclusão de castanha de caju não utilizada no experimento. Para essa estimativa, foi utilizado o PROC REG do programa Statistical... (1996). O modelo matemático adotado foi o que apresentou melhor adequação para o tipo de resposta biológica estudada. 


\section{RESULTADOS E DISCUSSÃO}

O consumo de matéria seca, expresso em quilograma por dia, e em porcentagem do peso vivo e da matéria seca em gramas por unidade de tamanho metabólico, não foi alterado em função da inclusão de CC na dieta (Tab. 3). Como os teores de extrato etéreo da ração ficaram abaixo de $8 \%$ na ração total (Tab. 2), este resultado é aceitável, uma vez que o Nutrient... (2001) estabelece essa porcentagem como limite, a partir do qual ocorreria redução no consumo de MS.
O valor médio de consumo de matéria seca foi de $21,29 \mathrm{~kg} / \mathrm{dia}$, superando em $11,2 \%$ o obtido por meio de simulação com o Nutrient... (2001), o qual estimou, para os animais experimentais, exigência de consumo de matéria seca em torno de $18,9 \mathrm{~kg} / \mathrm{dia}$. O mais alto consumo, provavelmente, foi resultado do potencial produtivo dos animais, aliado ao estádio de lactação em que se encontravam - pico de consumo - e à ração com disponibilidade de volumoso com adequado valor nutritivo. A média de consumo de matéria seca como porcentagem do peso vivo de 3,68 atesta esta afirmação.

Tabela 3. Consumo de matéria seca, matéria orgânica e nutrientes de vacas em lactação com diferentes proporções de castanha de caju na ração

\begin{tabular}{|c|c|c|c|c|c|c|c|}
\hline \multirow{2}{*}{ Nutriente } & \multicolumn{4}{|c|}{ Inclusão da castanha de caju (\%) } & \multirow{2}{*}{ EPM } & \multicolumn{2}{|c|}{ Contraste $^{1}$} \\
\hline & 00 & 08 & 16 & 24 & & $\mathrm{~L}$ & Q \\
\hline $\mathrm{MS}, \mathrm{kg}$ & 21,54 & 21,52 & 20,49 & 21,62 & 0,43 & 0,49 & 0,51 \\
\hline $\mathrm{MS}, \% \mathrm{PV}$ & 3,75 & 3,70 & 3,55 & 3,72 & 0,08 & 0,43 & 0,47 \\
\hline $\mathrm{MS}, \mathrm{g} / \mathrm{kg}^{0,75}$ & 183,36 & 181,46 & 173,64 & 182,60 & 3,74 & 0,44 & 0,47 \\
\hline $\mathrm{MO}, \mathrm{kg}$ & 20,35 & 20,51 & 19,42 & 20,35 & 0,42 & 0,61 & 0,66 \\
\hline $\mathrm{PB}, \mathrm{kg}$ & 3,52 & 3,68 & 3,29 & 3,24 & 0,10 & 0,91 & 0,60 \\
\hline $\mathrm{EE}, \mathrm{kg}$ & 0,72 & 1,05 & 1,53 & 1,65 & 0,05 & $<0,01$ & 0,31 \\
\hline $\mathrm{CNF}, \mathrm{kg}$ & 6,41 & 5,91 & 5,55 & 5,89 & 0,15 & 0,09 & 0,17 \\
\hline FDN, kg & 9,70 & 9,88 & 9,06 & 9,57 & 0,22 & 0,60 & 0,71 \\
\hline FDN, \%PV & 1,69 & 1,70 & 1,57 & 1,64 & 0,04 & 0,52 & 0,65 \\
\hline FDA, kg & 6,39 & 5,73 & 5,89 & 5,53 & 0,11 & 0,20 & 0,51 \\
\hline Cinzas, $\mathrm{kg}$ & 1,20 & 1,01 & 1,06 & 1,28 & 0,03 & 0,01 & $<0,01$ \\
\hline $\mathrm{Ca}, \mathrm{kg}$ & 0,16 & 0,18 & 0,16 & 0,16 & 0,003 & 0,27 & 0,14 \\
\hline $\mathrm{P}, \mathrm{kg}$ & 0,06 & 0,07 & 0,07 & 0,06 & 0,002 & 0,19 & 0,16 \\
\hline
\end{tabular}

00: sem CC; 08: com 8\% de CC na porção concentrada; 16: com 16\% de CC na porção concentrada; 24: com 24\% de $\mathrm{CC}$ na porção concentrada.

MS: matéria seca; MO: matéria orgânica; PB: proteína bruta; EE; extrato etéreo; CNF: carboidratos não fibrosos; FDN: fibra em detergente neutro; FDA: fibra em detergente ácido; Ca: cálcio; P: fósforo.

EPM: erro-padrão da média.

${ }^{1}$ Valor de $\mathrm{P}: \mathrm{L}=$ efeito linear; $\mathrm{Q}$ = efeito quadrático.

O consumo de proteína bruta foi próximo ao valor de $3,65 \mathrm{~kg} /$ dia estimado pelo Nutrient... (2001), não sendo obtidas alterações em seu consumo. Como as rações foram formuladas para serem isoproteicas e não sendo observadas alterações no consumo de MS, esse resultado era esperado.

A ingestão de EE aumentou linearmente em função dos teores crescentes de CC adicionados à ração, conforme a equação de regressão $\mathrm{Y}=$ $0,75+0,041 \mathrm{X}$, em que: $\mathrm{Y}$ é o consumo de EE em quilogramas e $\mathrm{X}$ corresponde à de inclusão de CC no concentrado (\%). O coeficiente de determinação para a equação foi de 0,96, e a probabilidade igual a 0,02. Conforme demonstrado pela equação, para cada $1 \%$ de adição de castanha de caju, o consumo de extrato etéreo aumentou $0,041 \mathrm{~kg}$.

O consumo de carboidratos não fibrosos, fibra em detergente neutro em quilograma por dia, fibra em detergente neutro como porcentagem do peso vivo e fibra em detergente ácido não variou com a adição de castanha de caju na ração.

Pimentel et al. (2007), ao utilizarem CC na dieta de vacas em lactação e cana-de-açúcar como volumoso único, encontraram redução significativa de 5,6\% no consumo de matéria 
seca total com a inclusão desse coproduto na ração de vacas leiteiras. Segundo esses autores, a proporção de $24 \%$ de CC no concentrado resultou em diminuição nos consumos de NDT, FDN e FDA em relação ao tratamento-controle, o que, possivelmente, deveu-se à diminuição no consumo de MS.

De acordo com Vargas et al. (2002), o efeito depressor dos lipídeos sobre o consumo de matéria seca pode estar relacionado à inibição do crescimento microbiano e, por consequência, fermentação da fibra, reduzindo, desta forma, a taxa de passagem da digesta pelo trato gastrointestinal. A inibição pode ser direta, por meio de efeitos citotóxicos sobre os microrganismos, ou indireta, por meio da substituição do carboidrato pelo lipídeo. Como os lipídeos não são utilizados como fonte de energia para o crescimento bacteriano, pode haver falta de energia fermentável no rúmen.

Os coeficientes de digestibilidade da matéria seca, da matéria orgânica e dos nutrientes apresentaram variações que não foram relacionadas ao aumento no teor de lipídeos das dietas com a inclusão de CC (Tab. 4). Os resultados deste trabalho são condizentes com as observações reportadas por Bateman II e Jenkins (1998), os quais não notaram efeitos da inclusão de lipídeos sobre a digestibilidade aparente desses nutrientes, sugerindo que quantidades significativas de lipídeos não protegidos podem ser adicionadas à dieta, pois não promovem efeitos na digestibilidade desses nutrientes.

Tabela 4. Coeficientes de digestibilidade aparente (\%) da matéria seca, matéria orgânica e nutrientes de vacas em lactação com diferentes proporções de castanha de caju na ração

\begin{tabular}{|c|c|c|c|c|c|c|c|}
\hline \multirow{2}{*}{ Nutriente } & \multicolumn{4}{|c|}{ Inclusão de castanha de caju (\%) } & \multirow{2}{*}{ EPM } & \multicolumn{2}{|c|}{ Contraste } \\
\hline & 00 & 08 & 16 & 24 & & $\mathrm{~L}$ & Q \\
\hline MS & 63,13 & 60,21 & 67,39 & 61,12 & 1,84 & 0,66 & 0,66 \\
\hline MO & 65,33 & 63,32 & 69,29 & 63,43 & 1,69 & 0,60 & 0,58 \\
\hline PB & 61,59 & 54,79 & 64,79 & 53,43 & 2,38 & 0,81 & 0,66 \\
\hline $\mathrm{EE}$ & 70,35 & 68,38 & 77,66 & 69,64 & 2,94 & 0,58 & 0,62 \\
\hline $\mathrm{CNF}$ & 86,00 & 86,97 & 87,86 & 90,45 & 0,77 & 0,93 & 0,60 \\
\hline FDN & 53,29 & 49,97 & 57,86 & 48,35 & 2,21 & 0,59 & 0,51 \\
\hline FDA & 54,11 & 41,37 & 59,09 & 47,83 & 2,70 & 0,90 & 0,90 \\
\hline
\end{tabular}

00: sem CC; 08: com 8\% de CC na porção concentrada; 16: com 16\% de CC na porção concentrada; 24: com 24\% de CC na porção concentrada.

MS: matéria seca; MO: matéria orgânica; PB: proteína bruta; EE: extrato etéreo; CNF: carboidratos não fibrosos; FDN: fibra em detergente neutro; FDA: fibra em detergente ácido.

EPM: erro-padrão da média.

${ }^{1}$ Valor de $\mathrm{P}: \mathrm{L}=$ efeito linear; $\mathrm{Q}=$ efeito quadrático.

A digestibilidade do extrato etéreo não foi diferente entre as rações, com média de $71,5 \%$. De acordo com o Nutrient... (2001), a digestibilidade dos ácidos graxos, componentes do extrato etéreo, pode ser influenciada pelo consumo de matéria seca, pela quantidade de lipídeo consumida e pelas características do lipídeo na ração basal e no lipídeo suplementar. O grau de insaturação é, possivelmente, a característica que mais influi sobre a digestão de lipídeos (Nutrient..., 2001). Portanto, a fonte ideal de lipídeo para vacas em lactação seria aquela que não interferisse na digestibilidade dos demais nutrientes, apresentando elevada digestibilidade intestinal. Embora apresente 78,7\% de ácidos graxos insaturados, a castanha de caju não influenciou a digestibilidade dos nutrientes. Possivelmente, o ácido oleico $57,4 \%$ dos ácidos graxos totais - não interfere tanto no ambiente ruminal.

Oliveira (2005), ao avaliar a inclusão de soja extrusada na ração de vacas em lactação, obteve médias de 69,$1 ; 70,9$ e 53,5\%, respectivamente, para os coeficientes de digestibilidade da MS, MO e FDN em rações com aproximadamente $6,4 \%$ de extrato etéreo. Os valores obtidos pelo referido autor foram mais altos que os obtidos no presente estudo, 61,1; 63,4 e 48,4\%, respectivamente, para a digestibilidade da MS, MO e FDN para as rações com 7,3\% de extrato etéreo. 
O tempo despendido com ingestão de matéria seca (min/dia) apresentou padrão decrescente com a inclusão da castanha de caju na ração (Tab. 5). Como não foi observada alteração na quantidade de matéria seca consumida, a redução no tempo de ingestão pode ser atribuída ao aumento na palatabilidade das rações em razão da adição de $\mathrm{CC}$. A inclusão de $\mathrm{CC}$ resultou em comportamento quadrático $(\mathrm{P}<0,01)$ para esta variável, indicando que o tempo de ingestão da ração com $8 \%$ de CC no concentrado diminuiu em relação à ração-controle, decrescendo ainda mais na ração com inclusão de $16 \%$ de CC ao concentrado e, posteriormente, aumentando na ração com inclusão máxima do coproduto.
Observou-se diminuição no tempo gasto com ócio concomitantemente ao aumento na atividade mastigatória. $\mathrm{O}$ tempo de ruminação tendeu a comportar-se da mesma forma que o tempo despendido com ingestão $(\mathrm{P}=0,05)$.

O tempo despendido com ingestão de água não foi influenciado pela inclusão de CC nas rações experimentais. Em média, as vacas gastaram 1,61 minuto bebendo água por quilograma de MS ingerida. Este valor foi mais alto que o encontrado por Oliveira (2005), de $1,25 \mathrm{~min} / \mathrm{kg}$ de MS, ao utilizar animais com produção média de $25,5 \mathrm{~kg}$ de leite.

Tabela 5. Comportamento ingestivo de vacas em lactação com diferentes proporções de castanha de caju na ração

\begin{tabular}{|c|c|c|c|c|c|c|c|}
\hline \multirow{2}{*}{ Variável } & \multicolumn{4}{|c|}{ Inclusão da castanha de caju (\%) } & \multirow{2}{*}{ EPM } & \multicolumn{2}{|c|}{ Contraste $^{1}$} \\
\hline & 00 & 08 & 16 & 24 & & $\mathrm{~L}$ & $\mathrm{Q}$ \\
\hline Ingestão, min/dia & 285,9 & 253,9 & 209,6 & 246,2 & 3,93 & $<0,01$ & $<0,01$ \\
\hline Ócio, $\mathrm{min} / \mathrm{dia}$ & 596,3 & 626,6 & 666,0 & 569,5 & 8,26 & 0,01 & $<0,01$ \\
\hline Ruminação, min/dia & 526,4 & 515,5 & 535,4 & 591,2 & 10,18 & 0,27 & 0,05 \\
\hline Ingestão de água, min/dia & 31,4 & 44,0 & 29,0 & 33,1 & 3,12 & 0,60 & 0,52 \\
\hline mastigatória & 812,3 & 769,4 & 744,9 & 837,4 & 9,31 & $<0,01$ & $<0,01$ \\
\hline \multicolumn{8}{|l|}{ Ingestão } \\
\hline Minutos/kg MS & 13,6 & 12,2 & 10,2 & 11,8 & 0,34 & 0,01 & 0,05 \\
\hline Minutos/kg FDN & 29,9 & 27,1 & 23,2 & 26,8 & 0,84 & 0,03 & 0,07 \\
\hline \multicolumn{8}{|l|}{ Ruminação } \\
\hline Minutos/kg MS & 24,8 & 24,12 & 26,1 & 28,0 & 0,63 & 0,72 & 0,33 \\
\hline Minutos/kg FDN & 54,8 & 53,0 & 59,3 & 63,9 & 1,61 & 0,78 & 0,33 \\
\hline \multicolumn{8}{|l|}{ Atividade mastigatória } \\
\hline Minutos/kg MS & 38,3 & 36,3 & 36,4 & 39,8 & 0,89 & 0,20 & 0,14 \\
\hline Minutos/kg FDN & 84,7 & 80,0 & 82,5 & 90,7 & 2,23 & 0,29 & 0,16 \\
\hline
\end{tabular}

00: sem CC; 08: com 8\% de CC na porção concentrada; 16: com 16\% de CC na porção concentrada; 24: com 24\% de CC na porção concentrada.

EPM: erro-padrão da média.

${ }^{1}$ Valor de $\mathrm{P}: \mathrm{L}=$ efeito linear; $\mathrm{Q}=$ efeito quadrático.

O tempo gasto com atividade mastigatória apresentou padrão quadrático quanto à raçãocontrole, decresceu na ração com 8 e $16 \%$ de CC no concentrado e aumentou na ração com maior proporção de CC. Embora tenha sido observada redução no tempo de ingestão de matéria seca na ração com 16\%, 209,6min/dia, e $24 \%$ de CC no concentrado, $246,2 \mathrm{~min} /$ dia, em relação à ração-controle, 285,9min/dia, o tempo despendido com ruminação possibilitou que a atividade mastigatória não fosse influenciada pela suplementação lipídica.
Os animais que receberam ração com $16 \%$ de CC no concentrado utilizaram menor tempo por quilograma de matéria seca e FDN ingerida em relação à ração-controle, provavelmente, devido às diferenças no tempo total gasto com atividade de consumo quando comparadas aos demais tratamentos. Houve efeito linear $(\mathrm{P}=0,01 \mathrm{e}$ $\mathrm{P}=0,03)$ da proporção de lipídeos na ração sobre o tempo de ingestão em min/kgMS e $\mathrm{min} / \mathrm{kgFDN}$. O tempo gasto com ruminação e atividade mastigatória, por quilograma de matéria seca e FDN consumido, não apresentou variação entre as rações avaliadas. 
Segundo Harvatine e Allen (2006), embora muitos experimentos tenham observado o consumo diário de matéria seca, poucos descreveram o comportamento ingestivo e mastigatório. Esses pesquisadores, ao avaliarem a suplementação lipídica e seus diferentes tipos, não observaram efeito da ração sobre o tempo despendido com consumo - média de 253,25min/dia -, no entanto lipídeo saturado aumentou linearmente o tempo de ruminação em relação à ração-controle e com lipídeos insaturados, tendo elevado o período de ruminação em até $56 \mathrm{~min} /$ dia. Esse aumento, de acordo com esses autores, parece ter sido causado pelo elevado fluxo de lipídeo saturado para o duodeno. A suplementação com lipídeo, nesse experimento, reduziu o consumo de água, presumidamente em razão do decréscimo na ingestão de matéria orgânica digestível no rúmen. A interação do tipo de lipídeo, ruminação e comportamento ingestivo com o consumo de líquido ainda não está esclarecida.

\section{CONCLUSÕES}

A maior proporção de castanha de caju adicionada à porção concentrada, 24\%, proporciona teor de extrato etéreo de 7,3\% à ração sem influenciar o consumo, a digestibilidade aparente e o comportamento ingestivo, podendo ser utilizada como fonte alternativa de lipídeo e proteína na dieta de vacas leiteiras em lactação.

\section{REFERÊNCIAS}

BATEMAN II, H.G.; JENKINS, T.C. Influence of soybean oil in high fiber diets fed to nonlactating cows on ruminal unsaturated fatty acids and nutrient digestibility. J. Dairy Sci., v.81, p.2451-2458, 1998.

CHURCH, C.D. Los lipídicos en la nutricíon de los ruminantes. In: CHURCH, D.C. El ruminante fisiologia digestive $y$ nutricion. Zaragoza: Acribia, 1988. 641p.

GRUMMER, R.R.; LUCK, M.L.; BARMORE, J.A. Rumen fermentation and lactation performance of cows fed roasted soybeans and tallow. J. Dairy Sci., v.76, p.2674-2681, 1993.
HARVATINE, K.J.; ALLEN, M.S. Effects of fatty acid supplements on feed intake, and feeding and chewing behavior of lactating dairy cows. J. Dairy Sci., v.89, p.1104-1112, 2006.

JOHNSON, T.R., COMBS, D.K. Effects of prepartum diete, inert rumen bulk, and dietary polyethylene glycol on dry matter intake of lactating dairy cows. J. Dairy Sci., v.74, p.933944, 1991.

LAVEZZO, O.E.N.M. Abacaxi, banana, caju, uva, maçã. In: SIMPÓSIO SOBRE NUTRIÇÃ̃O DE BOVINOS, 6.,1995, Piracicaba. Anais... Piracicaba: FEALQ, 1995. p. 291.

LIMA, M.L.M. Uso de coprodutos da agroindústria na alimentação de bovinos. In: REUNIÃO ANUAL DA SOCIEDADE BRASILEIRA DE ZOOTECNIA, 42., 2005, Goiânia. Anais... Goiânia: Sociedade Brasileira de Zootecnia: Universidade Federal de Goiás, 2005. p.446.

LOUSADA JÚNIOR, J.E; COSTA, J.M.C; NEIVA, J.N.M.; RODRIGUEZ, N.M. Caracterização físico-química de coprodutos obtidos do processamento de frutas tropicais visando seu aproveitamento na alimentação animal. Rev. Cienc. Agron. v.37, p.70-76, 2006.

NUTRIENT requirements of dairy cattle. 7.ed. Washington, DC: National Academy Press, 2001. 368p.

OFFICIAL methods of analysis. 16.ed. Arlington: AOAC International, 1995. 1025p.

OLIVEIRA, M.A. Proporção de forragem e teor de lipídeos na dieta de vacas leiteiras: consumo, produção e composição do leite. 2005. 54f. Dissertação (Mestrado em Zootecnia) - Escola de Veterinária, Universidade Federal de Minas Gerais, Belo Horizonte, MG.

PIMENTEL, P.G.; MOURA, A.A.A.N.; NEIVA, J.N.M. et al. Consumo, produção de leite e estresse térmico em vacas da raça Pardo-Suíça alimentadas com castanha de caju. Arq. Bras. Med. Vet. Zootec., v.59, p.1523-1530, 2007.

SNIFFEN, C.J.; O'CONNOR, J.D., VAN SOEST, P.J. et al. A net carbohydrate and protein system for evaluating cattle diets. II Carbohydrate and protein availability. J. Anim. Sci.,v.70, p.3562-3577, 1992. 
STATISTICAL Analysis System. User Guide: Statistics. Version 6.12 edition. Cary, NC: SAS Institute Inc., 1996.

VAN SOEST, P.J.; ROBERTSON, J.B.; LEWIS, B.A. Methods for dietary fiber, neutral detergent fiber, and nonstarch polyssacharides in relation to animal nutrition. J. Dairy Sci., v.74, p.35833597, 1991.

VAN SOEST, P.J. Nutritional ecology of the ruminant. 2.ed. Ithaca: Cornell University, 1994.
VARGAS, L.H.; LANA, R.P.; JHAM, G.N. et $a l$. Adição de lipídios na ração de vacas leiteiras: parâmetros fementativos ruminais, produção e composição do leite. Rev. Bras. Zootec., v.31, supl., p.522-529, 2002.

VILLELA, S.D.J; VOLTOLINI, T.V.; PIMENTEL, J.J.O. Formulação de rações para bovinos leiteiros. In: NEIVA, A.C.G.R.; NEIVA, J.N.M. (Ed) Do campus para o campo: tecnologias para a produção de leite. Brasil: Tocantins, 2006. p.320. 